\title{
ORA, NENHUM PESQUISADOR É IMORTAL ${ }^{1}$
}

\author{
WELL, NO RESEARCHER IS IMORTAL
}

\author{
Zélia Maria Viana Paim (UFSM)²
}

Resumo: Neste estudo, pretendemos identificar as tendências e as opções teóricas da linguista sulrio-grandense Neusa Carson. Nosso objetivo é descrever e interpretar textos seus publicados na Revista do Centro de Artes e Letras, UFSM, e em outras importantes revistas, Cadernos de Estudos Linguisticos, UNICAMP, Letras de Hoje, PUCRS, Boletim da ABRALIN, ABRALIN. A escolha teórico-metodológica da linguista, ao longo de sua produção acadêmica, delineia o caminho de seu fazer pesquisador, principalmente, em Linguística de campo. Na revista acadêmica, configura-se institucionalmente o lugar de circulação do conhecimento produzido por Neusa Carson na História das Ideias Linguísticas no sul do país.

Palavras-chave: Neusa Carson; revista acadêmica; Linguística de campo.

Abstract: In this study, we intend to identify the trends and options of the theoretical linguist from Rio Grande do Sul, Neusa Carson. We aim to describe and interpret her texts published in Revista do Centro de Artes e Letras, UFSM, and other important journals: Cadernos de Estudos Linguísticos, UNICAMP; Letras de Hoje, PUCRS; Boletim da Abralin, ABRALIN. The linguist's theoretical and methodological choice throughout her academic production shows her way of researching mainly on field linguistics. The journals are the institutional place of circulation of the knowledge produced by Neusa Carson in the history of linguistic ideas in the south of Brazil.

Keywords: Neusa Carson; academic journal; field Linguistic.

O presente estudo enquadra-se na perspectiva da História das Ideias Linguísticas e pretende identificar as tendências e as opções teóricas da linguista sul-rio-grandense Neusa Carson, cujos estudos sobre a língua Macuxi ${ }^{3}$ muito contribuíram para fazer avançar as pesquisas nesse domínio. Para tanto, procuramos descrever e interpretar os textos publicados na Revista do Centro de Artes e Letras, UFSM, e em outras importantes revistas, como Cadernos de Estudos Linguísticos, da UNICAMP, Letras de Hoje, da PUCRS, e Boletim da Abralin, da ABRALIN. À época dessas publicações, de 1979 a 1986, a linguista-pesquisadora ${ }^{4}$ ocupava o lugar de Professora Assistente do Curso de Letras no Centro de Artes de Letras (CAL) da

\footnotetext{
${ }^{1}$ Citação de CARSON (1986, p. 78).

2 Bolsista do Programa Nacional de Pós-Doutorado Institucional (PNPD) da Coordenação de Pessoal de Nível Superior (CAPES); Pesquisadora do Laboratório Corpus. E-mail: zeliamvp@gmail.com

${ }^{3}$ Embora a referida pesquisadora, em seus trabalhos, utilize o nome da língua "Macuxi" ora com inicial maiúscula e ora com inicial minúscula, optaremos, neste estudo, por utilizar a primeira forma.

${ }^{4}$ Cf. CARSON (1984), que usa "o linguista-pesquisador" para se referir ao seu fazer em Linguística.
} 
Universidade Federal de Santa Maria (UFSM), sendo que, em 1977, realizou pesquisa de campo em comunidades linguísticas Macuxi em Roraima. Como veremos, no decorrer deste estudo, Carson também realizou pesquisa em outras línguas - portuguesa e africana - a partir de dados de informantes distantes de sua vida nativa e a partir de pesquisa literária, respectivamente. Nosso interesse, portanto, recai sobre todos os textos de sua autoria publicados nas revistas acadêmicas anteriormente citadas.

Em nossa reflexão, consideramos que a revista acadêmica está a serviço da circulação do conhecimento e, nessa instância, "os dizeres são como se mostram", de modo que os meios para isso "não são nunca neutros" (ORLANDI, 2001, p. 11-12). A relação constitutiva entre produção e circulação leva-nos, necessariamente, a pensar não só em sentidos, mas "em movimento, de sujeito, de ideias que circulam e deixam de circular, para voltar a circular em outro lugar, em outro momento, com outros sujeitos e outras instituições" (SCHERER, 2005, p. 24), movência que se dá em/entre revistas acadêmicas.

No caso deste estudo, os artigos de Carson constituem nosso arquivo, a partir do qual levantamos os temas trabalhados e a bibliografia referida - e isso é tudo o que consideramos de fundamental importância para entendermos as tendências e as opções teóricas de Carson bem como para podermos tratar dessa história das ideias. Os artigos são os seguintes:

- O Português do Brasil, um Crioulo?, 1979a; Macuxi (Caribe) e os Universais de Greenberg, 1981a; Análise Linguística: Coleta de Dados, 1981b; Ação Coordenada para Documentação das Linguas Indígenas da Amazônia, 1986, publicados na Revista Do Centro de Artes e Letras;

- Recentes Desenvolvimentos em Macuxi (Caribe), 1983, publicado em Cadernos de Estudos Lingüísticos;

\section{Letras de Hoje; $e$}

- Relações Semântico-Sintáticas em Macuxi, 1979b, publicado em

- Problemas de Análise linguistica em Linguas indígenas brasileiras, 1984, publicado no Boletim da Abralin.

Somado a esses artigos, está um conjunto de material informativo que se constitui, principalmente, por textos como apresentação, ficha catalográfica, elementos editoriais e informações colhidas na página do Centro de Artes e Letras (CAL), na Biblioteca Central e também na Biblioteca Setorial (Centro de Educação) da UFSM, os quais servem para entendermos essa história das ideias.

Segundo Guimarães (2004, p. 11), é preciso considerar "uma análise das obras específicas pertinentes às instituições em que este saber se constitui e os acontecimentos que, nestas instituições, catalisam aspectos específicos da 
produção deste saber". Isso justifica nossa entrada na análise pela Revista do Centro de Artes e Letras e a posterior relação com as outras revistas, conhecidas nacionalmente e com publicação ainda corrente, Cadernos de Estudos Linguísticos, Letras de Hoje e Boletim da Abralin. Nesse percurso, procuramos entender os sentidos que nelas ressoam, a partir da produção de um mesmo sujeito linguista.

Iniciamos por classificar a Revista do Centro de Artes e Letras como "periódico serial". Pertencem a essa espécie "as publicações que sejam montadas a partir de contribuições não induzidas e que apresentem um intervalo de circulação de fascículos superior a seis meses" (TRZESNIAK, 2000, p. 21-22). A revista foi publicada pelo CAL/UFSM sob responsabilidade de um presidente e de uma equipe editorial. Sua publicação ocorre de 1979 a 1997, quando foi substituída por Expressão, revista do Centro de Artes e Letras, de publicação corrente.

O CAL foi concebido na estrutura antiga da UFSM e sua história está relacionada à Faculdade de Belas Artes, fundada em janeiro de 1963. Nessa, o primeiro curso a ser fundado foi o de Música e, o segundo, o curso de Desenho e Plástica, ambos em 1964. O curso de Letras passou a integrar a UFSM em 1965, funcionando no âmbito da Faculdade de Filosofia, Ciências e Letras. Com a reestruturação administrativa da UFSM, em 1979, o Curso de Letras foi incorporado à Faculdade de Belas Artes, que passou então a ser nomeada Centro de Artes e Letras, CAL. Também fazem parte do CAL os cursos de Desenho Industrial e de Artes Cênicas, que funcionam desde o final da década de 70 .

O primeiro número da Revista do Centro de Artes e Letras foi publicado no mesmo ano de incorporação do curso de Letras ao CAL e contava com um total de 112 páginas, divididas entre 8 artigos. A tiragem inicial de 500 exemplares repetiu-se até 1994, exceto entre os anos de 1987 e 1989, quando a tiragem foi de 550 exemplares, voltando aos 500 exemplares no ano seguinte. Sempre produzida pela Imprensa da UFSM, a revista passou a ter ISSN em 1983, sob o número 0101-8264. Apresentou a mesma programação visual de capa por 18 anos: a fotografia de Agueda Franceschet serviu à elaboração da programação feita pelo professor Reinaldo Pedroso, do CAL (Figura 01). 

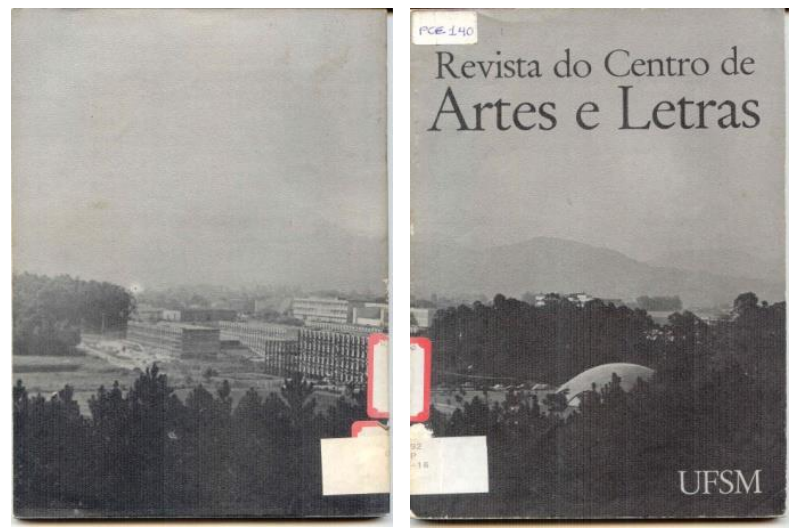

Figura 01 - Revista do Centro de Artes e Letras, v. 1, n. 1, 1979.

A revista teve periodicidade semestral entre os anos 1979 e 1983, era publicada em dois volumes, com o primeiro correspondendo aos meses janeiro/junho e o segundo aos meses julho/dezembro. Depois, de 1983 a 1996, a revista passou a ter um volume anual, compondo dois números que correspondiam aos meses janeiro/dezembro. Os anos de 1993 e 1994, correspondentes aos volumes 15 e 16, respectivamente, foram editados em um único exemplar.

Nesses números, são publicadas conferências ${ }^{5}$ escolhidas entre as proferidas durante o I Seminário Internacional Interdisciplinar, ocorrido entre 4 e 5 de julho de 1993. Esse evento foi promovido pela UFSM, Centro de Artes e Letras, Curso de Mestrado em Educação, Federação de Arte - Educadores do Brasil e Associação Gaúcha de Educadores. O tema foi "As transformações do conhecimento na virada do século". A Comissão de Ensino, Pesquisa e Extensão (CEPE/CAL) reponsabilizou-se pela organização dessa publicação.

Considera-se, segundo Scherer (2003, p. 77), que a "revista não preexiste aos enunciados que a exprimem, nem aos objetos simbólicos que a completam. Os dois são essenciais para que ela exista". Assim, o Editorial, sem assinatura, refere ao ano de 1979 como sendo o marco final da construção do prédio de Artes e do acréscimo das Letras às Artes, reunidas no CAL. Segundo consta no Editorial, as finalidades da Revista do Centro de Artes e Letras, enquanto "órgão de comunicação e divulgação de nosso Centro são várias", muito embora sejam salientadas duas finalidades principais, a saber:

[...] aquelas que mais de perto dizem respeito ao Professor e ao aluno: para o Professor, seja um instrumento capaz de servir de veículo às suas ideias

\footnotetext{
${ }^{5}$ Entre as conferências publicadas, encontra-se Entremeio e Discurso, de Eni Puccinelli Orlandi (IEL/UNICAMP).
} 
amadurecidas no estudo sério; para o aluno, igualmente sirva para a divulgação do que for de valor, ou sirva de leitura para o aperfeiçoamento de seu aprendizado $^{6}$ (REVISTA DO CENTRO DE ARTES DE LETRAS, 1979, p. 7).

Nesse primeiro número, oito artigos de professores do CAL/UFSM são publicados e, segundo o Editorial, "valem como trabalho publicado para fins de titulação" (p. 3). A segunda revista publicada corresponde ao número 2, do primeiro volume, num total de 95 páginas, numeradas de 113 a 208, correspondendo aos meses julho/dezembro. O editorial, assinado pelo Prof. Dr. Frederico Richter (presidente), salienta que, "após o êxito de estreia da Revista do Centro de Artes e Letras, eis-nos diante da responsabilidade de um segundo número, ou seja, o de manter o padrão inicial e quiçá, elevá-lo" (1979a, p. 3). É a partir desse número da revista que Neusa Martins Carson publica seus artigos.

No primeiro artigo publicado, O Português do Brasil, um Crioulo?, dividido nas seguintes partes: 0. Introdução; 1. A ordem SOB em Macuxi; 2. Discussão; e 3. Conclusão, Carson (1979a) ocupa-se de dados linguísticos na obra de autores do fim do século XIX e meados do século XX, voltados para o contato linguístico entre portugueses e africanos. A autora visa a determinar até que ponto o português do Brasil, em certas áreas afastadas dos grandes centros, pode ser considerado como crioulizado. Para isso, os dados foram obtidos em fontes artísticas e literárias, como canções populares, diálogos de romances, etc., e em fontes oficiais, como dados estatísticos e documentos legais.

Segundo Carson (1979a), era difícil determinar a procedência linguística dos africanos trazidos para o Brasil, pois os senhores de escravos procuravam adquirir escravos de tribos diferentes. A grande quantidade de escravos transportados para a Bahia e Rio de Janeiro fez com que, nem sempre, os escravagistas pudessem manter a determinação de não aglomerar falantes do mesmo grupo linguístico. Numerosos são os falantes, numerosos são os grupos informados pelos autores pesquisados. De acordo com Carson (Ibid., p. 119), entre os escravos, existiam os chamados "negros novos", aqueles que, recém-chegados ao Brasil, falavam apenas a sua própria língua, bem como os "ladinos", que já falavam o Português ao chegarem no Brasil.

A hipótese inicial de Carson (1979a, p 118) era de que "o falar dos brasileiros deve ter-se impregnado de influência do falar dos escravos", a partir do grande número de africanos, cerca de doze milhões, em comparação com o pequeno número de colonizadores portugueses, em torno de dois milhões e quatrocentos mil, até 1850. No decorrer da pesquisa, com base na análise de dados de autores estudados, Carson (Ibid., p. 123) aponta que não há evidência de que o contato das línguas africanas com a língua portuguesa tenha

${ }^{6}$ Optamos por manter a ortografia original em todas as citações. 
provocado uma "alteração violenta e inesperada nesta, a ponto de produzir um pidgin português e mais tarde, consequentemente, um português crioulizado, nas definições ortodoxas desses conceitos". Para ela, aquilo que bloqueou o "surgimento de um português pidginizado, foi o uso de línguas francas africanas no Brasil. O Yoruba, Kimbundo e talvez Huasá desempenharam esse papel" (Ibid., p. 123). O que ocorreu, segundo Carson, foi o acréscimo de numerosos vocábulos de origem africana ao português, especialmente no que tange à culinária, à religião e aos instrumentos musicais.

A autora toma, como base teórica para esse artigo, autores que realizaram estudos de descrição da língua portuguesa a partir da década de 20 do século XX. Salienta Carson (1979a, p. 118) que, nesse momento, "as variações linguísticas constatadas no falar dos brasileiros são tomadas como mudanças da língua e não mais encaradas como corruptela de um estágio mais puro da mesma". Assim, a pesquisadora busca autores que trabalham com a descrição da língua caipira, como Amaral (1920), com a descrição da língua portuguesa, Câmara (1969); com a unidade linguística, Elia (1971), e com a dicionarização do folclore brasileiro, Cascudo (1962), além de historiadores como Freyre (1936), entre outros.

No segundo artigo, Macuxi (Caribe) e os Universais de Greenberg, dividido em: 0. Introdução; 1. A ordem SOB em Macuxi; 2. Discussão; e 3. Conclusão, Carson (1981a) trata dos princípios universais da ordem das palavras, conforme proposta de Joseph Greenberg (1963). A autora apresenta Macuxi ${ }^{7}$ como exemplo de uma língua cuja ordem das palavras é SOB (Sujeito - Objeto - Verbo), ordem essa que não contradiz os princípios estabelecidos por Greenberg. Assim, Carson (1981a) opõe-se à descoberta de Desmond Derbyshire para outra língua, Caribe, Hiskaryana, do norte brasileiro, cuja ordem é OVS (Objeto - Verbo - Sujeito).

Nesse artigo, escrito a partir de uma comunicação motivada pelos dados analisados em sua tese de doutorado ${ }^{8}$, Carson mostra que a língua

7 "A língua Macuxi é falada no Brasil, no Território Federal de Roraima, em malocas localizadas
entre $4^{\circ}$ e $6^{\circ}$ graus a norte do Equador, por mais de 4.000 falantes" (CARSON, 1983, p. 90). Em
artigo inédito, intitulado Preservação da Lingua e Cultura entre os Macuxi (Caribe), que faz parte do
Fundo Documental Neusa Carson (FDNC), Carson (s/d, p. 2-3) escreve: "A língua Macuxi
pertence à família Caribe e é o segundo grupo mais numeroso do Brasil (tucuma tem o maior
número de falantes) com aproximadamente 15.000 falantes". "[...] O grupo vive entre 3 e 4 graus
norte e 60 a 61 graus oeste. Seu território compõe-se principalmente de savana, o que quer dizer
vegetação baixa e esparsa e palmeiras de buriti nas margens dos riachos. Os macuxi localizam-se
na bacia do Rio Branco, especialmente seus afluentes Tacutu e Uraricuera. Ainda encontram-se
caça, pesca e frutos em abundância nessa área. A área compreende 213.000Km ${ }^{2}$ e
aproximadamente 35.000 índios vivem ấ". Esse artigo está arquivado, provisoriamente, sob o n.
368, no Arranjo Documental do FDNC, na Série 4 - Atividades de Pesquisa, Ensino e Extensão.
8 "Phonology and Morphosytax of Macuxi (Caribe), Dissertação de Doutorado, U. of Kansas, 1981";
"Phonology and Morpho-Syntax of Macuxi (Carib). EUA, University of Kansas, 1982"; ambas as
maneiras são referenciadas por Carson (1983, 1984). 
Macuxi não é um contraexemplo aos universais de Greenberg. A autora propõe a realização de "mais pesquisa para determinar se outras línguas Caribe seguem a ordem das palavras como em Macuxi ou como Hiskaryana" (CARSON, 1981a, p. 66). A análise tipológica de outras línguas da família Caribe "determinará até que ponto os universais propostos por Greenberg têm validade para todas as línguas; ou para algumas somente, o que diminui a validade dos princípios estabelecidos dos universais da linguagem", conclui Carson (1981a, p. 66).

A autora toma Greenberg (1963) como base para discussão sobre a gramática da língua Macuxi. Considera, então, os seguintes critérios: (1) a língua tem, principalmente, três posições ou pós-posições; (2) a ordem relativa do sujeito, verbo e objeto em orações declarativas com sujeito, verbo e objeto nominal; (3) a posição dos adjetivos qualificativos com relação ao substantivo para mostrar que a língua Macuxi é uma língua SOV. Além de Grenberg, a autora faz referência a Derbyshire (1977) e Megliazza (1977). A pesquisadora trabalha a ordem dos elementos na língua a partir da proposição dos universais e, também, com inquérito linguístico, adentrando no campo da Antropologia.

No terceiro artigo, Análise Lingüistica: Coleta de Dados, dividido em I Introdução; II Análise dos dados elicitados; 1. Análise segmental; 2. Análise supra-segmental; e III Conclusão, Carson (1981b) dirige-se ao principiante em pesquisa de campo e mostra como os instrumentos de trabalho e a confiança no informante constituem partes importantes da experiência bem sucedida desse fazer em Linguística. A autora salienta que igualmente importante para os bons resultados da análise linguística é a qualidade dos dados e seu tratamento sistemático através da teoria linguística.

Para a aplicação prática no campo linguístico, Carson (1981a, p. 209) realiza a análise fônica da língua Luganda, da família bantu de línguas africanas: "Luganda é uma língua do tronco lingüístico Benue-Congo, do sub-tronco Bantu, [...] também conhecida como Ganda, é a língua nacional de Uganda". Os dados para a análise "foram coletados de janeiro a junho de 1974, com o Sr. Swali, na universidade de Ohio State, Ohio" (Id, p. 206). Conforme a autora, é desejável, para a investigação da língua, uma amostragem dos consultores que inclua: diferentes faixas etárias em ambos os sexos, certa posição de liderança no local de residência e personalidade extrovertida. Neste caso, o entrevistado escolhido era doutorando em Agronomia na Universidade de Obio State.

Com base no pressuposto de que o linguista desconhece a língua que irá analisar, Carson recomenda que uma língua em comum deve ser estabelecida, nesse caso, o inglês. A pesquisa parte então de um vocabulário mínimo para fazer a análise fonêmica da língua Luganda. A pesquisador esperava encontrar determinados fatos linguísticos, entre eles, fonemas segmentais e suprassegmentais. Carson (1981b, p. 209) explica que: “Tais 
fonemas se estruturam em sílabas, que por sua vez, se estruturam em morfemas e palavras". Salienta, ainda, que esse estudo, em particular, "por sua natureza ilustrativa do método de trabalho de análise e atamento de uma amostra de dados, não pretendeu ser exaustivo" (CARSON, 1981b, p. 209).

A bibliografia utilizada para esse artigo tomou como base autores cujos métodos linguísticos garantiram uma sistematização de dados fonéticos da língua, isto é, dos fonemas segmentais foram analisados a distribuição alofônica, a palatalização e a labilização; dos suprassegmentais, foram analisados a duração e o acento tonal. Para tanto, a linguista tomou como base a constituição do vocabulário mínimo sugerido por Alexandre (1972) e Swadesh (1975) bem como guias de classificação de línguas indígenas americanas elaborados por Loukotka (1968) e Ruhlen (1967).

Até aqui, descrevemos e analisamos os artigos publicados na Revista do Centro de Artes e Letras, do CAL (UFSM). Antes de passarmos a descrever e a interpretar o último artigo de Carson publicado nessa mesma revista, buscamos em outras revistas acadêmicas, a saber, Cadernos de Estudos Linguísticos, Letras de Hoje e Boletim da Abralin, os artigos Relações Semântico-Sintáticas em Macuxi, 1979b; Recentes Desenvolvimentos em Macuxi (Caribe), 1983; e Problemas de Análise linguistica em Linguas indígenas brasileiras, 1984, a fim de tratarmos de sentidos que neles ressoam, dizendo da produção do mesmo sujeito linguista pesquisador.

É com base nos problemas apontados por Carson (1984), relativos a duas ordens na pesquisa de campo - os de ordem extralinguística: mobilidade, informantes e materiais; e os de ordem linguística: limites e método -, que buscamos Carson (1979b) e Carson (1983) para dar conta de nosso objetivo neste estudo, qual seja, identificar as tendências teóricas e metodológicas da pesquisadora.

Nessa perspectiva, ao tratar dos problemas relativos à mobilidade restrita na pesquisa de campo ou na pesquisa in situ, a linguista aponta, como entraves ao seu fazer de pesquisadora, fatores administrativos, econômicos e geográficos, entre outros. Essa mobilidade restrita ao linguista deve-se ao fato da pouca importância que as autoridades administrativas conferem à pesquisa em línguas indígenas. Segundo Carson (1984, p. 131-132), se a área da pesquisa está sob jurisdição da FUNAI, existem regras a serem cumpridas, como "provas de boa saúde, vacinas várias, além de um plano ou proposta de trabalho detalhado". Se missões católicas ou evangélicas atuam na área de pesquisa, os critérios não são claros. Essas "aceitam o pesquisador se este demonstra engajamento com as causas defendidas por sua missão" (CARSON (1984, p. 132). Essa situação coloca o linguista pesquisador em posição quase insustentável: 
[...] de um lado, o desejo de parte de certos órgãos, que se mantenha alheio aos problemas não-linguísticos da comunidade em estudo e de outro, que seja o mais atuante possível, sob pena de não ser autorizado. Ora, o linguista traz consigo uma determinada visão de mundo, bastante idealismo (senão não estaria na área), mas seu objetivo primeiro, naquele momento, é coletar dados linguísticos de uma língua de que talvez seja o único a ter acesso (CARSON, 1984, p. 132).

A autorização para a mobilidade do linguista pesquisador, depois de cumpridas todas as exigências, não é garantida devido à "orientação prévia que tem que ser satisfeita e que independe da contribuição científica do pesquisador" (Ibid., p. 132). Se o pesquisador recebe a autorização, deve encontrar, 'por sua conta em risco', meios para se locomover até o interior, onde vivem os falantes da comunidade linguística. Assim, o pesquisador depende de horários e possibilidades de auxílio da FUNAI ou da missão que o recebe, de lugar nas conduções que se deslocam para o interior, ou contrata, com recursos próprios, seu meio de transporte. Mesmo quando tudo favorece o deslocamento, ocorrem fatores que impedem a mobilidade, como clima, terreno acidentado, falta de condições de voo, entre outros.

Superada a questão da mobilidade, a pesquisadora volta-se para a escolha de informantes. Diante disso, Carson (1984, p. 132-133) orienta que devemos privilegiar aqueles indivíduos "com personalidade mais extrovertida e até considerados pelos outros como melhores falantes de sua própria língua". Estes indivíduos demonstram maior aptidão para "colaborar com os propósitos do pesquisador" e, normalmente, desempenham um papel de liderança em seu grupo, como "o chefe, o professor, o enfermeiro, o pajé, a matriarca" (CARSON, 1984, p. 133).

De acordo com Carson (Id, p. 133), entre as informantes mulheres, a melhor escolha deve recair sempre nas "mulheres mais idosas", uma vez que essas "costumam ser informantes monolíngues, o que tem grande utilidade na coleta de literatura oral, como lendas e cantos". As histórias coletadas com falantes idosas da língua podem esclarecer "uma forte tendência à alternância do acento tonal alto e baixo" em enunciados longos, segundo Carson (1983, p. 96). A partir dessas informantes, a extensão dessa tendência e a interação entre tom, entonação e ritmo da língua podem ser investigadas.

A pesquisa linguística com informantes distantes ou afastados de sua vida nativa perde a "naturalidade contextual", segundo Carson (1984, p. 133). No entanto, a dificuldade de chegar à comunidade faz com que o pesquisador busque, por exemplo, na Delegacia da FUNAI, no hospital ou na Casa do Índio, nas missões ou nas escolas, indivíduos falantes da língua escolhida, para se familiarizar com a mesma até chegar ao local de concentração de seus falantes. Ao lançar mão desses recursos, o pesquisador "sempre tem que ter presente a irrealidade da situação, ou seja, do contexto de fala" (CARSON, 1984, p. 133), surgindo problemas com relação "à incerteza quanto ao uso de 
uma forma ou de outra, quase sempre sobrevindo dúvidas, especialmente com elementos dêiticos da língua" (Ibid., p. 133). Além disso, observa a pesquisadora que a aculturação provoca alterações inevitáveis na fonologia, na gramática e no vocabulário.

Além desses, outros problemas podem advir do material linguístico coletado. Carson (1984, p. 132) aponta aqueles que "incluem o uso de vocabulários previamente organizados pelo pesquisador". De acordo com a linguista, a lista de palavras apresentadas ao informante serve somente no início da pesquisa, "pois elas não têm um contexto de maior ocorrência, seja linguístico ou cultural, incorrendo-se no período de grosseiros nivelamentos ou de simplificação de fatos muito complexos da língua" (CARSON, 1984, p. 132). Assim, o posicionamento da linguista é de que a pesquisa conduzida in situ consegue resultados mais satisfatórios quanto à qualidade do corpus. Entretanto, Carson (1983, p. 137) adverte que, se o problema essencial do linguista pesquisador é "descrever línguas, conforme usadas por uma comunidade de língua", este é cada vez um problema maior "pela assimilação dos indígenas à comunidade branca, na melhor das hipóteses, ou outras causas, nos casos mais tristes".

As questões administrativas e econômicas refletem-se também nos escassos recursos relativos ao material do pesquisador, como gravador, pilhas, fitas, papel e lápis, além de tudo o mais que torna esses objetos operacionais. Acrescentam-se o material de uso pessoal do pesquisador, desde a rede de dormir até seus alimentos, sem esquecer que "sempre se corre o risco de ter de se desfazer deles quando a canoa ou avião estiver com excesso de carga" (CARSON, 1984, p. 133).

Todos esses problemas administrativos e econômicos determinam, de certa forma, o limite da pesquisa. Para isso, a linguista aponta as seguintes necessidades: um plano detalhado do trabalho a ser executado e um método escolhido para o desenvolvimento do mesmo, os quais concorrem efetivamente para que a pesquisa de campo chegue ao seu término com sucesso, em razão do tempo curto para a sua realização. Os limites da pesquisa estabelecidos de início, previamente ao levantamento dos dados da língua, facilitam a elaboração do relatório final exigido pelas entidades governamentais. Esse plano depende então do tipo de público que o pesquisador espera atingir, de quanto já foi feito na língua, decorrente da revisão da literatura relacionada.

Segundo Carson (1983), a documentação da língua Macuxi, através de vocabulário coletado, iniciou em 1832, com o austríaco J. Natterer. As primeiras gramáticas foram elaboradas por religiosos da Guiana Inglesa: Williams (1923) e Father Keary (1924). O método de descrição dos dados coletados de uso mais corrente entre os pesquisadores de línguas de povos sem escrita, de acordo com Carson (1984, p. 134-135), "são os preconizados pelos 
estruturalistas neo-blonfieldianos (Hockett, 1955) e pelos tagmêmicos (Elson e Pickett, 1962)". Estes últimos, de acordo com a pesquisadora (1983; 1984), são missionários evangélicos, orientados pelo Summer Institute of Lingusitics (SIL), como a maioria que estuda o Macuxi e adentrou o território brasileiro a partir da década de 50, a saber, Hawkins (1950), Foster (1959), Burns (1963), Hodsdon e Lowe (1974), Hodsdon (1976) e Abbott (1976).

Outras análises de línguas indígenas realizadas utilizam a teoria prosódica de Birth (1984) ou a teoria gerativo-transformacional. De acordo com Carson (Ibid., p. 135), as análises fonológicas utilizam o modelo de "Chomsky e Hale (1969) ou de variantes dessa teoria". Nesse caso, na década de 80, para a fonologia do Macuxi, a referência é Carson (1981). A semântica estrutural, com base em Lyons (1977), pode ser de grande auxílio para mostrar a organização da língua Macuxi no paradigma de alimentos, segundo a pesquisadora (1979b). Ainda, outro exemplo de método de análise citado diz respeito à aplicação de "teoria linguística do Círculo de Praga" (CARSON, 1984, p. 135). A respeito dos métodos e teorias aplicadas, a linguista observa que:

A utilização consistente de qualquer método baseado em modernas linguísticas
sempre resulta em um trabalho homogêneo e de valor para o linguista. Mas se
ainda não foi feita uma descrição da língua nos moldes estruturalistas,
inicialmente, torna-se bastante difícil o uso de teorias recentes, como a
transformacional, já que essa teoria propõe o uso da intuição do falante de que
carece o pesquisador, ao menos em seu contato inicial com a língua, como o
antropólogo, o pedagogo e o missionário, o trabalho será mais acessível e,
portanto, de maior utilidade, se estiver em conformidade com os moldes
estruturalistas descritivos, com o qual são familiarizados (CARSON, 1984, p.
135).

Para a linguista, embora a análise linguística detecte as relações sintáticas e semânticas da língua, é a observação do mundo biossocial, portanto, considerações pragmáticas, que permitem concluir a análise. Nesse sentido, afirma que as relações linguísticas de sintaxe e semântica só podem estar completas com a observação do falante da língua em seu ambiente natural, uma vez que, para a autora (1979b, p. 60), "não basta a mera descrição do sistema intralinguístico".

Esse é um problema fundamental para o linguista que manuseia dados de uma língua já não mais falada. Do mesmo modo, a descrição in situ é um problema para o linguista, pois, de acordo com Carson (1984, p. 136), “os exemplos de língua indígena em desaparecimento são demasiado numerosos para que não nos inquietemos", embora haja, além desses, mais riscos. Segundo Auroux (1998, p. 96), "é a diversidade, a multiplicidade e a contingência do real que impõe os verdadeiros limites - o real, o falso e o viver. 
Somos livres para inventar os padrões e as regras que pouco a pouco arrancam a vida de sua contingência"”.

Em seu último artigo publicado na Revista do Centro de Artes e Letras e intitulado Ação Coordenada para Documentação das Linguas Indígenas da Amazônia, apesar de as inquietações da linguista marcarem o seu mesmo lugar, elas passam a assumir outro viés. Esse é um trabalho apresentado no simpósio "Descrição e Preservação de Língua Indígena da Amazônia" por ocasião da 35. ${ }^{a}$ Reunião Anual da SBPC, ocorrida em 1983, em Belém - Pará. Neste artigo, dividido em Introdução; Coletas de dados para a descrição; Arquivo de documentos; Normas aos pesquisadores; Depósito da documentação; Manutenção e distribuição; e Conclusão, Carson (1986) procura alertar para "a necessidade de uma ação coordenada entre instituições e indivíduos a fim de recolher e salvaguardar a documentação original sobre as línguas da Amazônia" (Ibid., p. 68), pois essas se encontram ameaçadas de extinção.

Carson chama a atenção das instituições brasileiras que fornecem auxílio a pesquisadores de línguas indígenas, para a exigência, além de artigos escritos, de fitas magnéticas e respectivas transcrições. Para o trabalho de descrição e análise, as fitas originais devem ser arquivadas e devem ser usadas somente as cópias destas. De acordo com a linguista (1986, p. 69), a comunidade científica deve "preocupar-se em conservar os dados coletados, dando-lhes o resguardo e divulgação devidos". A pesquisadora considera que, após operar, durante anos, com uma língua ou família de línguas, as fitas gravadas, os fichários, as transcrições fonéticas e muito material coletado são engavetados para análise posterior, a qual muitas vezes nunca chega a se concretizar.

É possível que grande parte do trabalho realizado pelo pesquisador fique então perdido para a ciência linguística. No entanto, poderia estar disponível, com menos dificuldade, se a comunidade de linguistas pudesse contar com um sistema de documentação central de línguas indígenas no país. Para Carson:

A documentação poderia ser guardada em um arquivo central para línguas indígenas, o que se julga de urgência absoluta para o bem da ciência e dos próprios indígenas e seus descendentes, devendo guiar-se por certas linhas diretrizes (CARSON, 1986, p. 69).

Assim, entidades patrocinadoras de pesquisa precisam "estabelecer metas prioritárias tanto às línguas a serem descritas como às normas básicas a serem seguidas" (id, p. 70). Este órgão centralizador poderá treinar o

\footnotetext{
${ }^{9}$ No original: “C'est la diversité, la multiplicitá et la contingence du réel qui posent les vrais limites - le réel, il faut le vivre. Libre à nous d'inventer les standards et les régles qui peu à peu arrachent la vie à sa contingence" (AUROUX, 1998, p. 96).
} 
pesquisador, com um menor investimento de recursos financeiros. Poderá ser mantido através de fundos que poderiam advir dos próprios usuários e/ou de financiadoras governamentais, como CAPES e CNPq. (CARSON, 1986). O centro de documentação central de línguas indígenas poderá ser responsável por manter a circulação da informação do material em sua posse, cadastrando "não só os pesquisadores e interessados na área, como também departamentos de Linguística, bibliotecas nacionais e associações nacionais e internacionais de Linguística" (Ibid., p. 71). A este órgão caberá também a recuperação de informações coletada no passado sobre línguas indígenas brasileiras.

Esse arquivo, na falta de lugar próprio, poderá funcionar em museu ou biblioteca pública, contanto que ofereça todas as garantias exigidas por tal material, composto por cópias impressas ou microfilmadas e por fitas magnéticas, as quais não podem ser afetadas por condições climáticas adversas, atmosfera poluída, luminosidade excessiva, etc. (CARSON, 1986, p. 71). A documentação deverá ser, ainda, adequadamente catalogada e submetida à padronização, quanto ao tamanho e tipo de papel e fita magnética a serem utilizados.

Em relação ao pesquisador, o arquivo deverá respeitar os direitos autorais sobre o material depositado por certo prazo de tempo. Aquele pesquisador que coletou os dados de determinada língua terá o privilégio de trabalhar com eles por um prazo determinado. Após esse prazo, o material poderá ser utilizado por outros, para outras pesquisas. Carson (1986, p. 72) chama a atenção de que "Em caso de morte ou doença irreversível do pesquisador, o prazo original de seu privilégio poderá ser abreviado". A autora conclui que, para a concretização da ideia proposta, será necessária uma ação conjunta de instituições de ensino e pesquisa, de pesquisadores individuais e de órgãos financiadores.

A bibliografia usada para esse artigo, além de Glenn (1983), Rankin (1983) e Winn (1983), é constituída de Cartas recebidas com informações sobre arquivo, datadas de 6 de julho; documentação de línguas indígenas da América do Norte, datada de 2 de maio; e materiais e fitas de pesquisa de campo, resultantes de auxílio dos Fundos de Pesquisa Jacobs, datados de 16 de junho, respectivamente. A pesquisadora refere também a linguística de campo a partir de Samarin (1967) e a informações obtidas na Biblioteca Central da Universidade Federal de Santa Maria.

Em nossa reflexão, podemos apontar que a Revista do Centro de Artes e Letras configura-se como espaço de circulação de conhecimento sobre línguas - africana, portuguesa e indígena -, do fazer do pesquisador de campo e de diretrizes para a criação de um arquivo de documentação da língua indígena, a partir dos artigos publicados pela linguista pesquisadora, Neusa Martins Carson. 
Observamos que, no campo da pesquisa linguística na UFSM, nas décadas de 60 e 70, segundo Scherer (2005, p. 23), "os conteúdos privilegiados eram a diacronia e a língua escrita, e em outros, a sincronia e a língua falada". Nesse sentido, os estudos realizados por Carson estão em sintonia com a linguística brasileira que começa a considerar "o fenômeno linguístico desde as línguas indígenas até o português falado nas grandes cidades". Em relação às décadas de 60 a 80, Altman (1998, p. 178) destaca "a diversificação da Linguística em dois grupos de especialidade: os que faziam parte da Linguística Pura e os que faziam parte da Linguística Aplicada".

É nesse momento histórico-político de definição de campos e divisão em especialidades linguísticas que Carson realiza pesquisa de campo, ou in situ, segundo Auroux (1998), "linguística de terreno", um conceito recente, datado do século XX. Mas o que é terreno e linguística de terreno para o autor citado? Em suas palavras:

\begin{abstract}
Pode-se dizer que é um espaço delimitado no qual se encontram os locutores pessoas dotadas de capacidades linguísticas - um ambiente cultural e um ambiente natural. O que é específico disso que se chama linguistica de terreno é a ideia que, para construir representações linguísticas, é preciso que um observador penetre em tal terreno e se torne parte de uma relação face a face e individual ${ }^{10}$ (AUROUX, 1998, p. 89) [grifos do autor].
\end{abstract}

É essa a condição que sustenta o trabalho em Linguística de campo, cujos resultados foram publicados nos seguintes artigos: Relações SemânticoSintáticas em Macuxi, 1979b; Recentes Desenvolvimentos em Macuxi (Caribe), 1983; Problemas de Análise linguística em Linguas indígenas brasileiras, 1984. Neles, Carson trata de questões que dizem respeito à mobilidade, ao recrutamento de informantes, às gravações do corpus; aos objetos de trabalho de campo, conhecimentos que dizem respeito às condições de produção do linguista pesquisador.

Além da pesquisa de campo, a linguista realizou pesquisa com informantes distantes ou afastados de sua vida nativa. $\mathrm{O}$ estudo junto a um falante da língua Luganda, na Universidade de Ohio, resultou no artigo intitulado Análise Linguística: Coleta de Dados. O segundo informante, um falante da língua Macuxi, foi seu auxiliar entre 1978 e 1981, tendo estudado em Santa Maria, Rio Grande do Sul. Parece-nos que o primeiro artigo que a linguista publicou, Macuxi (Caribe) e os Universais de Greenberg, a partir de seu trabalho de

${ }^{10}$ No original: "On peut dire que c'est un espace délimité das lequel se trouvent des locuteurs -
des gens doués de capacités linguistiques -, un environnement cultural et un environnement
naturel. Ce qui est spécifique de ce que l'on appelle linguistique de terrain, c'est l'idée que, pour
construire des représentations linguistiques, il faut qu'un observateur pénètre sur ledit terrain et
devienne partie prenante d'une relation face-à-face et individuelle" (AUROUX, 1998, p. 89). 
tese, intitulado Phonology and morphosyntax of Macuxi (Carib), 1981, seja também resultado desse auxílio.

Entendemos que é em seu último artigo, Ação Coordenada para Documentação das Linguas Indígenas da Amazônia, 1986, que a linguista não só aponta a urgência de um arquivo de documentação da língua indígena, como também traça diretrizes para constituição desse arquivo, comprometendo-se com o impensado sobre a questão da linguística de campo no início da década de 80 do século XX. Esse último artigo é o encerramento de um longo trabalho de pesquisa de campo que iniciou em 1977 e, por isso, é também um inventário de sentidos que a constituem como linguista-pesquisadora da língua indígena, linguista essa que mobiliza, em seu caminho de produção científica, saberes advindos de diferentes teorias e métodos de pesquisa. É assim que, na Revista do Centro de Artes, configura-se institucionalmente o lugar de circulação do conhecimento linguístico produzido por Neusa Martins Carson, cujos sentidos ressoam também em outras revistas acadêmicas, configurando e constituindo a História das Ideias Linguísticas no sul do país.

\section{REFERÊNCIAS}

ALTMAN, Cristina. A pesquisa linguística no Brasil (1968-1988). São Paulo: Humanitas/FFLCH/USP, 1998.

AUROUX, Sylvain. Les enjeux de la linguistique de terrain. In: Langages, 32e année, n. 129, p. 89-96, 1998. Disponível em: <http://www.persee.fr/web/revues/home/prescript/article/lgge_0458-

726X_1998_num_32_129_2148> Acesso em: 1 ago. 2013.

CARSON, Neusa Martins. O Português do Brasil, um Crioulo? In: Revista do Centro de Artes de Letras. Universidade Federal de Santa Maria, Centro de Artes e Letras, Santa Maria/RS, v. 1, n. 2, p. 113-208, jul./dez. 1979a.

. Relações Semântico-Sintáticas em Macuxi. In: Letras de Hoje. Porto Alegre/RS, PUCRS, n. 37, p. 53-62, set. 1979b.

- Macuxi (Caribe) e os Universais de Greenberg. In: Revista do

Centro de Artes de Letras. Universidade Federal de Santa Maria, Centro de Artes e Letras, Santa Maria/RS, v. 3, n. 1, p. 7-140, jan./jun. 1981a. - Análise Linguística: Coleta de Dados. In: Revista do Centro de

Artes de Letras. Universidade Federal de Santa Maria, Centro de Artes e Letras, Santa Maria/RS, v 3, n 2, p. 141-250, jul./dez. 1981 b.

- Recentes Desenvolvimentos em Macuxi (Caribe). In: Cadernos de

Estudos Lingüísticos 4, Lingüística Indígena e Responsabilidade Social, Campinas, SP: UNICAMP/IEL, p. 89-104, 1983. Disponível em: <http://www.iel.unicamp.br/revista/index.php/cel/article/download/3535/ $2983 \%$ E2\%80\%8E> Acesso em: 6 jul. 2013. 
. Problemas de Análise linguística em Línguas indígenas brasileiras. In:

Boletim da Abralin, p. 131-138, mar. 1984.

- Ação Coordenada para Documentação das Línguas Indígenas da

Amazônia. In: Revista do Centro de Artes de Letras. Santa Maria, RS:

Universidade Federal de Santa Maria, Centro de Artes e Letras, v. 8, n. 1-2, p. 5-98, jan./dez. 1986.

GUIMARÃES, Eduardo. Metodologia: História do saber e instituições. In:

História da Semântica: Sujeito, sentido e gramática. Campinas, SP: Pontes, p. 11-49, 2004.

ORLANDI, Eni P. Discurso e Texto: formulação e circulação dos sentidos. Campinas, SP: Pontes, 2001.

REVISTA DO CENTRO DE ARTES DE LETRAS. Santa Maria, RS: Universidade Federal de Santa Maria, Centro de Artes e Letras, v 1, n 1, p. 1112, jan./jun. 1979.

SCHERER, Amanda E. A história e a memória na constituição do discurso da linguística aplicada no Brasil. In: CORACINI, M. J.; BERTOLDO, E. S (Orgs.). O desejo da teoria e a contingência da prática: discursos sobre e na sala de aula. Campinas, SP: Mercado de Letras, p. 61-82, 2003. . Linguística no sul: estudos das ideias e organização da memória. In: GUIMARÃES, E.; BRUM de PAULA, M. R. (Orgs.). Sentido e Memória. Campinas, SP: Pontes, p. 9-26, 2005.

TRZESNIAK, Piotr. A concepção e a construção da revista científica. In: II Encontro de Editoração Científica e Cultural/IVFeira Pan-Amazônica do Livro. Anais... p. 21-34. Belém/PA: MPEG-Museu Paraense Emilio Goeldi/ABEC-Associação Brasileira de Editores Científicos, 2000. Disponível em:

<http://academia.edu/872626/A_concepcao_e_a_construcao_da_revista_cie ntifica $>$ Acesso em: 1 jul. 2013. 